\title{
The Strategic Transformation of Automobile Industry in China
}

\author{
Som Techakanjanakit \\ School of Management, Wuhan University of Technology \\ 122 Luoshi Road, Hongshan District, Wuhan 430070, Hubei, China \\ Tel: 86-186-7239-9237_E-mail: som7125@hotmail.com \\ Meifang Huang (Corresponding author) \\ School of Economics, Wuhan University of Technology \\ 122 Luoshi Road, Hongshan District, Wuhan 430070, Hubei, China \\ Tel: 86-186-7239-9537_E-mail: huang20091008@hotmail.com
}

Received: May 28, 2012

Accepted: July 2, $2012 \quad$ Published: July 15, 2012

doi:10.5430/ijfr.v3n3p8

URL: http://dx.doi.org/10.5430/ijfr.v3n3p8

\begin{abstract}
In the past few years, the global automobile industry is developing difficultly because of the influence from the financial crisis. In contrast, China's automobile production and sales are still having a blowout type growth, and jumped into the world's largest automobile production and sales market. At the same time, Chinese automobile companies continue to deepen and join with international brand cooperation; independent research and development of the independent brand production, and their technical also get greatly strengthened. Similarly, in the tide of industrial upgrading and international acquisitions, strategic transformation era of Chinese automobile industry has gradually started. This paper based on the world economic crisis brought both challenge and opportunity to the automobile industry in China, comprehensively analysis China's automobile industry development present situation and development trend in the transformation era, with case analysis of China's automobile companies, and then gives some suggestions on China's automobile industry strategy adjustment in transformation.
\end{abstract}

Keywords: Strategic transformation, Automobile industry, China automobile development

\section{Introduction}

Changing is the eternal theme of enterprise development. The strategic change is not only the result of environmental changes of the product, but also the outcome of the enterprise internal development pressure. Automobile enterprise is an organization of the high technology industrialization and commercialization and its purpose is to make profit. The globalization of economic and high diversity means of new technology enterprise competition, the market competition became more intense, and the enterprise metabolism speed up, which makes high technology and new technology enterprise face an increasing survival pressure in the market. The market is the foundation of the enterprise's survival; the enterprise strategy must comply with the needs of the market. The present market is changing fast, the automobile industry enterprise will undoubtedly need to pay more attention than ever to the strategic management, when the current strategy can not follow the change of environment, then they need to change it in time, to make a strategic transformation and adjustment. Therefore, the success or failure of the strategic transformation involves what factors, and which is the key factor have become the enterprise decision makers highly concerned problems, the purpose of this study is to find the influential key factors of automobile industry strategic change, and analyzes the effect factors of its importance, and then puts forward some guidance strategic change for other enterprise to make strategic decisions.

\section{The Strategic Transformation and Its Influencing Factors}

\subsection{The Connotation of Enterprise Strategic Transformation and Its Literature Review}

The transformation strategy is refers to a process, in which the enterprise according to its external environment, the enterprise internal resources and capacity situation to overcome the difficulties. The enterprise faces in the original management pattern and access to a new competitive environment and design enterprise's future goals. The ways achieve them, and then form the new technology, new product and new market. The strategic transformation is the 
highest form of strategy and the adjustment of transformation. It is the results of enterprise external forces, and the internal forces promote the enterprise strategic adjustment and reformation. Its main manifestation is the key technology of the enterprise, product structure, and target market of business model to do adjustment and make decision. The essence of the strategy transformation of the enterprise is to achieve sustainable development and sustainable management goal and an exhaustive change. For, the enterprise it is a new life, it is the positive change for the enterprise.

Through the research of the enterprise strategic transformation, it is better to provide guidance for the enterprise's growth. Strategic transformation is the business enterprise's growth process that every enterprise has to meet in the process of making strategic choice, and it occupies a very important position. Once the enterprise growth meet some frustration, it is necessary to do strategic transition. The study of strategic transformation for enterprise can provide corresponding guidelines to its practical operation. An enterprise may also through the process of implementing the strategic transformation to reduce the blind behavior and invalid trial and error, reduce strategy transformation cost and improve the efficiency of the transformation, so as to improve the success rate of strategic transformation. Enterprise can get sustainable competitive advantages through the successful strategy transformation. In order to prevent the risk that the product or the decline of the industry may bring to the enterprise, the enterprise must be accurately and timely implement strategy transformation, so as to decline the loss on products or industry that the enterprise resources may bring to the enterprise.

So far, there is no special book written about enterprise strategic transformation, however, many strategists are aware of the strategic transformation is a profound enterprise reform. The scope of the enterprise reformation can be divided into the following categories: for the purpose of improve process performance process, to redesign the process of the existing innovation as the foundation, abandon the existing process of reengineering from scratch with the whole enterprise restructuring of the strategic transformation. Organizational change experts, Kurt Lewin, put forward the reform trilogy: Defrost, Mobile, and Freeze. Richard Pascale and Tonyathos put forward the basic frame structure transformation $7 \mathrm{~S}$ mode, point out that in order to understand the mechanism of organizational transformation and make the performance improvement target, an organization should achieve consistently and balance in seven aspects. These seven aspects are Strategy, Skills, Values, Structures, Systems, Staff, and Style. Strategy, Structure and System are considered to be the essential "hardware" elements of enterprise's success, and Style, Staff, Skills and Values are considered to be the "software" elements of the enterprise with a successful management. "Software" elements and the "hardware" elements are equally important. John Kotter put forward the eight steps mode of the transformation in the article "the leadership change" set up the sense of urgency, the formation of the powerful guiding power, vision and strategy formulated, vision to communicate and fully empowered to achieve our vision of employees, harvest short-term results, consolidating achievement and create further reform, and make new method institutionalization. Kotter researched more than 100 companies and found that the basic goals of the enterprise reform is to fundamentally change the enterprise's management practices, help the enterprise to adapt to a more challenging new market environment. Jack T. put forward the ten commandments in the article "implementing the change ", and points out that the organizational transformation should also focused on two aspects, the organization for change "Readiness" and the ability of change "Capability". The preparation for transformation depends on whether there is enough motivation and whether it can get in benefits from the transformation. The ability to transformation depends on whether there is enough support, conditions and skills to complete the change. PWC company put forward 15 guiding principles in this paper "Better Change: Best Practices for Transforming Your Organization" in 1995. This 15 guiding principles are: face the reality, focus on strategic issues, make strong call on, set range wisely, establish strong change atmosphere, let customers drive the change, get knowledge about the stakeholders, do continuous communication, reconstruction assessment index, make full use of all change means, with a view of the long term, consider about the diversity, establishing the integration of skill, plans and the action. The Boston consulting group's vice president Jeanie Daniel Duck in the article "The Management Transformation" put forward: managers should not divide change down into sporadic clips, and should think about transformation on the point of supervision system changes.

David pointed in a book "the strategic management" about there are three strategic transformation methods: forced change strategies, education reform strategy, rational make the change of strategy. Jack Duncan thinks that rational change strategy that should be includes the following four steps: the first step, invite employees to participate in the change and specific process of transformation. The second step, in order to promote reform, some incentive is needed; self-interest is one of the most important incentives. The third step, for making people to understand the purpose of transformation, we need to spread and communication. The fourth step, send and receive feedback, everyone is pleased to know how things are going on, and made what progress they have. They have all emphasized to overcome change resistance, think that the most important factor of the failure is resistance. 
To sum up, we can see that so far all of the literature about the enterprise strategic transformation are on some varying degree emphasize on the enterprise strategic management and its control, thus made clear strategy transformation as basic steps to make a comprehensive system of change. However, there is hardly any research about the factors of the impact the transformation strategy, if the enterprise wants to get a successful implementation of strategic transformation, must analyze the influence factors of its success or failure first, and then start from these aspects.

\subsection{The Analysis of Transformation Strategy Influence Factors}

Strategic transformation is a complex multi-objective decision making, which is jointed by many subjective and objective factors; it is decided not only by the enterprise internal resources and ability, but also by the outside environment. Thus, this paper will concrete analysis the internal and external influence factors of automobile enterprise strategic transformation, in order to make the operator can fully consider about their importance. Only if the enterprise can recognize these the specific factors that influence the strategy transformation, clear all the advantages and disadvantages that the enterprise has, then they can lay the foundation for strategic transformation. It is considered that, the major factors that influence automobile enterprise strategic transformation are as follows: national/industry environment, strategic management, operation management, technology management, human resources. Every factor has its assessment criteria:

National/industry environment assessment criteria: the government encourages and preferential policy, industrial competitive situation, national macroeconomic conditions, association of industry competition situation, the industrial policy and regulation, industrial potential competitors.

Strategy management assessment criteria: enterprise idea/vision/target communication, enterprise social capital and the interpersonal network, the business's strategic vision, enterprise scale and international status, enterprise strategic alliance.

The management assessment criteria: management team's quality and ability, enterprise's information collection and report, organization and operation mechanism, the internal control mechanism.

Technical management assessment criteria: technology innovation ability, input intensity of the research and development, technology absorption/using ability, the core technology level, inventions and patents.

Human resources assessment criteria: human resources quality, interpersonal cooperation and exchange, performance management, executive officers/employee training, employee's loyalty.

Today's era is the strategy wins era, in order to participate in the competition and won a competition, it is important for an organization to make their strategy and tactics. The right strategy can make the organization improve their environment strain capacity, development and strengthen capacity; conversely, the wrong strategy will make the organization lost competitive advantage in the competition, and even fall or bankruptcy. Therefore, the strategic management as a new management concept has been at the core position of modern management. Based on the above analysis, we put forward assumption 1: strategic management has great impact on the automobile enterprise strategic transformation.

Some scholars believe that in the strategic transformation of a enterprise, the operators' decisions play a decisive role of the strategy to make the success or failure of the strategic transition, so they think the enterprise management strategies have the biggest influence on enterprise strategy transformation. But it is also considered that, enterprise social capital, the interpersonal network and the quality and strategic vision of operators are the key factors. Then we put forward hypothesis 2: in the strategic management assessment criteria, enterprise social capital and the interpersonal network and the strategic vision of the operators are the most important factors of the enterprise strategic transformation.

Talents are the most important resource of an enterprise; it is the basic power of the enterprise in the market competition and the development. Therefore, we put forward assumption 3: among the factors which have influence in enterprise strategic transformation, human resources management is more important than technology.

\section{The Present Status of China's Automobiles Industry Development}

Since the outbreak of the global economic crisis the second half of 2008, countries and regions in the world including China having made great efforts on the economic situation's refreshing. "Strategic transformation " seems to have become the only way for the development of the economy, and as the "industry in industrial" car industry is considered to be economic development's "four-wheel driver", should consider how to deal with this transformation era, how to make a luxuriant turn to realize changing from quantitative to qualitative changes? So, scientific master transformation era of automobile enterprise strategic has the very vital significance on the adjustment of China's automobile industry model, even to the China's economy. 


\subsection{China's Automobile Industry Development History}

Automobile industry in China has an history of more than 60 years, since half a century ago, the scale of the automobile industry experienced its born and its childhood, and from a limited amount the constant development and to the expansion. At present, the automobile industry has become an industry combined with car manufacturing, circulation and comprehensive service, and became an important factor that promote the economic growth, drive the development of relative industries of national economy and become the most important pillar industry China.

Since new China was founded until the reformation and opening-up, China's automotive industry started from scratch, and got the initial development in the 60s, through which it had formed a vehicle system such as carriages and SUVs, and the product gave priority to sport utility. But the automobile industry development speed was slow in this stage, the automobile companies are small scaled, scattered layout, and with the high cost, by 1978, China automobile yield only 150000 vehicles.

After the reformation and opening up, the country stepped up investment on automobile industry, increase the mini cars, heavy units, car manufacturers' construction, improved the product structure and improved the production automobile products fast. Especially in the $90 \mathrm{~s}$, the country issued first automobile industry policy (1994), different the ownership of the subordinate relationship such as state-owned car company and multinational automobile company, set up several joint venture enterprise, cars become the main development direction, and made the automobile industry in our country entering a rapid development stage, the product structure was diversified trend, car output was growing fast.

By the end of 2001, China joined to the WTO, and the car started mass into Chinese families, joint ventures and the independent brand enterprise grew rapidly, the domestic automobile industry came into the stage of speeding up. Annual output in 2002 breakthrough 3 million, and 2004 breakthrough 5 million cars, 2006 with an annual sale of more than 7.2 million vehicles, and annual car production was up to 7.2797 million vehicles. By 2009, China's annual car production and sales were respectively 13.791 million vehicles and 13.6448 million vehicles, year-on-year growth were $48.30 \%$ and $46.15 \%$, and China became the biggest country in the world in the field of car production and sales. This shows that the automobile industry in China has entered a period of rapid development of industry and rapidly expanding production. The Figure1 shows China domestic car sales simulations in nearly six months. Figure2 shows the China's whole automobile sales from 2010 to 2012 . We can see from the figure 3 and figure 4 that the car market in China is stably large.

\subsection{The Necessity of China's Automobile Industry Strategic Adjustment in the Transformation Era}

China's automobile industry has experienced the long-term development; China's automobile industry has been got certain development either from the aspect of "quality" of or from the aspect of "quantity". However, we should also be awareness of behind the sharp rise in China's automobile production; China's automotive core competitiveness of the enterprise didn't get the ascension coordinate with the production. Whether in the key parts of automotive spare and the independent innovation and independent intellectual property rights, or in high value added service industry in the current situation of the automobile development, China's automobile industry is still at a relatively low state in the global value chain of the car industry. China's automobile industry“s upgrading and strategy transformation are imperative.

\subsubsection{New Opportunities That China's Automobile Industry Is Facing in the Transformation Era}

On one hand, financial crisis brought some opportunities to China's automobile industry. It is well known that since the outbreak of the American financial crisis, the American automobile market suffered a heavy blow which is relying too heavily on financial market. With the spread of the financial crisis, the financial crisis began spreading to the entity economy, global car industry were all involved. This financial storm came from Wall Street had started to move the global automobile industry's original pattern, but where will it put the global car industry to? We can see that the American automobile industry and the major U.S. car companies have been hit by the crisis, and dragged back the global automobiles sales increase; But those who do not depend on the development of the automobile finance car market in the economic storm did not hurt vigor, such as China's automobile industry showed strong growth momentum in the financial storm. So the global automobile industry reconfiguration will again by the storm. Therefore, the financial storm is a missed opportunity for China's automobile enterprise. The international automobile industry recession, industry will appear phenomenon of capacity surplus. These capacity surpluses include talents and technology, etc. Many foreign development companies, design companies benefit may nosedive. And this provides a once-in-a-generation opportunity for the China's automobile market certainly to make acquisition, merger and mining talent.

On the other hand, the industrial transformation and upgrade bring some opportunities to China's automobile industry.

The industry transition upgrade is to change from the low added value to high added value upgrade, from a high energy consumption and high pollution to low energy consumption and low pollution upgrade, and from extensive to intensive 
upgrade. On the background of traditional energy nervous, economic market depression, economic energy-saving automobile industry will have great opportunities for development. Meanwhile, global climate change conference in Copenhagen put forward "the low carbon" concept increasingly thorough this trend. All of these are driving the whole car industry transformation and upgrading. Although China's traditional automobile technology lags behind of developed countries, but in the new energy vehicles field, it stands in the same starting line with foreign enterprises in developed countries. This means that in the future of the global market, who can get the core technology of new energy vehicles first, who can lead the new era of the automobile industry.

\subsubsection{China's Automobile Industry's New Challenges from Transformation Era}

China automobile enterprises face challenges in cross border mergers acquisitions. In recent years, China's automobile enterprise transnational M\&A cases of foreign car companies are common occurrences, such as SAIC motor acquisition South Korea Ssangyong, and Geely takeover Volvo. So how to successfully completing the acquisition process and how to run the target enterprise after the acquisition, make the enterprise of purchasing and even China's automobile industry can get benefits, those become a challenge for the enterprise transnational M\&A. For most Chinese automobile companies, internationalization is a new course, they don't have any mature textbooks and examples that can imitate, especially in overseas investment in factories and operation, the Chinese enterprises are the lack of analyzing and understanding the on this aspects: the local climate and geographic features, laws and regulations, the technical barriers, the intellectual property rights protection, product certification examination and approval, culture and life habit, market of brand promotion, customer relationship management and after-sales service, product design and quality, export order, ocean is carried etc. SAIC acquisition Ssangyong is a very good example, SAIC group officially acquisition SSangyong $48.92 \%$ equity with $\$ 500$ million in 2004 , but SAIC didn't get out of trouble after acquisition Ssangyong, but in the third quarter 2008 appeared the losses of 100 billion. In January 2009, Ssangyong car had gone into the "enterprise retro gradation program". SAIC motor paid much dearly for its tuition.

The challenges China's automobile industry is facing on core technology research and development.

From the independent research and development capacity, at present, among the automobile industry in China, only the truck enterprise have a strong independent research and development ability, and in the car key components such as the gearbox and engine technology field we still have a very big disparity with foreign advanced enterprise. As we can see from the figures below, china's own brand cars take very few market shares. At the same time, although China's new energy vehicle development is standing at the same starting line with foreign development countries' enterprise, but still has certain disparity in automotive electronics, such as automobile necessary technology. See from the independent brand, among the domestic dozens of major car models, only about CHERY, Giovanni GEELY, and several other domestic of independent brands, the others all are for introducing models. Of course, it isn't strange, because the independent research and development ability of independent brand behind will inevitably lead to the loss. Therefore, if China's automobile industry wants to grasp the initiative under the background of adjustment the global car industry pattern, it is also facing a great challenge in the core technology development.

\subsection{Some Countermeasures on China's Automobile Industry Strategic Mode Adjustment under the Transformation Era}

As mentioned above, China's automotive industry is facing many opportunities and challenges in such a transformation era. China's automobile industry through long-term development, has accumulated a lot of industry senior factors for the further development, the strategic mode in the sense of traditional is facing a new challenge, China's automobile industry need to adjust the strategy as soon as possible, so as to grasp the initiative in the new round of international industrial division. This paper put forward the following countermeasures according to the China automobile industry faces several key problems.

\subsubsection{China Automobile Enterprise Transnational M\&A Strategic Orientation and Conformity Strategy}

The Geely automobile succeed in buying the world's second largest gearbox producers DSI, then acquired Volvo car company $100 \%$ equity and related assets with $\$ 1.8$ billion, including intellectual property rights. Under the big trend of the automobile industry global value chain transfer to the developing countries, it is believed that there would be more Chinese car companies will acquire foreign cars well-known enterprise.

This paper argues that, the first thing China's automobile enterprise should do in the process of transnational M\&A is to reconsider enterprise strategic positioning. China enterprise must be very clear in acquiring overseas: and not hope that through acquisitions in developed countries can make market growth to further change or benefit, most of all are through the transnational M\&A to receive foreign enterprise of advanced technology, research and development team and advanced management concept, and thus enhance the enterprise its competition ability in the global market. It comes to the conclusion from this financial crisis that, the core of the future the global car market should including China, India, 
which countries have the rapid growth of the emerging market, only if firmly grasp the market, can firmly grasp the future direction of the automobile industry.

In addition, the integration strategy after the merger is important link to determine the effect on the merger. Among them, the integration of assets is mainly the merger of both parties of the enterprise assets split up, combination, optimum allocation process, it should be based on the effective integration and injected the practice of enterprise in different asset. Although most people believe that the integration of assets is mostly focused on fixed assets integration, but this paper will focus on the value of the intangible assets value, to the brand enterprise, it is an important intangible asset, and for the car companies because of consumption time lag, the brand is especially important. After the merger shall timely integration two enterprise's brand, keep the original brand of the company that was taken over, and provides the powerful follow-up guarantee, make the brand further work smoothly, and make intangible benefits for the M\&A enterprise. And M\&A can also do brand integration and adjustment according to the market situation and its own development strategy.

Finally, the enterprise culture integration is also the key of China's automobile enterprises' transnational M\&A. From the case study of SAIC mergers and acquisitions, we can draw the conclusion: the incompatible enterprise culture hasn't got good integration is an important reason for the failure to merge. Attention should be paid to control the differences of subculture, the subculture of informal organization and formed organization has extremely important influence on formal organization's activities. The conflict of the enterprise culture comes from the different view in different positions, China's automobile enterprise's merger and acquisition activity is inevitably have to communicate with the international automobile enterprises, cultural differences between different countries and regional will inevitably have influence in China's automobile enterprise's merger and integration. To fully realize the difference in the cultural conflict is the root of the merger's troubles. After the merger of the integration, the subculture system of the two enterprises must be united to a new enterprise culture in general, and cultural integration and reconstruction is a recessive and work for a long time. So whether the target enterprise's evaluation before the acquisition or the enterprise integration problems after the merger, fully research should be done on both sides of the enterprise merger culture and corporate culture background, find out the differences of culture and the culture difference of concrete micro reflected, to find specific measures for the cultural integration.

\subsubsection{China Automobile Enterprises' Independent Innovation Strategy and Brand Strategy}

This paper thinks that, in order to improve our car companies the independent innovation capability, the first is to find a suitable road for its actual situation of independent innovation, this is a kind of inevitable. But here, this paper also need to emphasize that the automobile industry in China is an international industry, whether the research and design of the car, or spare parts purchase, and the whole car sales, all have realized the internationalization from different extent.

Although the current Chinese automobile industry needs the independent innovation, but it is not meant to be closed doors, it also needs to strengthen technical cooperation with foreign enterprises, absorb foreign advanced experience, and it is not contradictory with independent innovation. For example, in April, 2010, Chery and the world's leading electric car infrastructure provider Better Place signed a cooperation agreement, jointly developed the electric car new technology. Figure 5 shows the compare of self-innovation brand with China overall automobile industry. We can see that there are remained large spaces for independent innovation in China automobile industry.

Secondly, it should be able to grasp the relationship between the short-term interests and long-term interests, realize transformation from the pursuit of the number to pursue quality. The Chery company research for A3 cars takes five years, during which it had repeatedly delayed time to the market. As Chery100th referral vehicles, this new model used the independent research and development of high efficiency and energy saving ACTECO engine and the CVT transmission. At the same time, it used the high strength steel beam, and carrying ESP electronic stability system, takes the passive and active dual safety performance into account. So far, Chery has already have complete and mature research and development department, already have a comparable technical strength with international brand, the A3 cars will no doubt be a" the milestone" in cars in the development. At the same time, in the new energy technology, Chery spent a great deal of intellectual and financial resources in a short period, realized the new energy technology broken bureau, and become leader of the new energy vehicles industrialization.

From current situation of the development of some Chinese automobile companies such as the Chery Company and Geely company, we can draw the conclusion: in the past, China's automobile enterprise was often eager to hope for success in the road of independent innovation, the speed of the new product launch was too fast, and it made a dazzling, but in fact it was slick. So, innovation has to be proper, should take the long-term and short-term interests into account, not to be slow or be fast. Fast will lead to false, slow will lose the opportunity, so enterprise need to have patience and grasp the modern market demand exactly in the independent innovation. 
Finally, the enterprise's independent innovation also needs to build a good enterprise creative culture, and create a ready to innovation atmosphere, do up to the leaders, down to the ordinary employees, all are ready to play to their intelligence. As long as the measures correctly, the system is reasonable, in all staff in wide consensus, even if be millet and rifle, it also can get out of a successful road.

\section{Conclusion}

China automobile industry should follow the green development way. From the level of development, the collapse of the tariff barriers is a kind of trend. China's automobile industry on the one hand have to face the fierce market competition, but also face a harsh reality, and that is the domestic traffic environment pollution and foreign green trade barriers. Automobile industry in China must face the reality, and follow the green environmental protection road, so that it can get out of the lowlands, become a pillar industry with high international competition ability. In addition to the above, the China automobile industry should build itself innovation products with promoting its own core technology. In a word, the development of China's automobile needs all the support from the government, the consumers and itself.

\section{References}

Bai, Z. L, \& Wang, W. L. (2000). China automobile industry market analysis and optimization strategy. China financial and economic publishing house.

Chen, Y. Y. (2009). Enterprise merger mode and success of internal conditions research. Economic theory and business management (4th). [Online] Available: http://dlib.edu.cnki.net/kns50/detail.aspx?dbname=CJFD1999\&filename=JJLL904.009.

China Automobile Industry Association Statistical Information Nets [DB].

Li, P., \& Zhang, J. (2010). The future development mode of automobile industry. Internet Fortune (14th). [Online] Available:

http://dlib.edu.cnki.net/kns50/detail.aspx?filename=WLCF201014067\&dbname=CJFD2010\&filetitle=\%e6\%b1\%bd \%e8 \%bd\%a6\%e8\%a1\%8c\%e4\%b8\%9a\%e6\%9c\%aa\%e6\%9d\%a5\%e6\%b8\%a0\%e9\%81\%93\%e5\%8f\%91\%e5\%b1\%95\%e6 $\% \mathrm{a} 8 \% \mathrm{a} 1 \% \mathrm{e} 5 \% \mathrm{bc} \% 8 \mathrm{f}$

Porter, M. (2002, January). The national competitive advantage of nations ( $1^{\text {st }}$ ed.). The Macmillan press LTD.

Renmin University of China newspaper data center. The management science, (2004-2007).

Shanghai automobile strategic website: http://www.autostr.org

Wang, B. L. (2007). The Policy System for Improving the Competitiveness of China s Automobile Industry. China Soft Science, [Online] Available: http://dlib.edu.cnki.net/kns50/detail.aspx?dbname=CJFD2007\&filename=ZGRK200711006

Yang, D. J. (2008). Independent GVC Model: A Reliable Upgrading Path of China s Automobile Industry. Journal of Industrial Engineering and Engineering Management, (2). [Online] Available: http://dlib.edu.cnki.net/kns50/detail.aspx?dbname=CJFD2008\&filename $=$ GLGU200802033

Yu, S. (2010). The financial crisis under the effect of M\&A economics $\left(2^{\text {nd }}\right)$. Hubei Social Science. [Online] Available: http://dlib.edu.cnki.net/kns50/detail.aspx?dbname=CJFD2010\&filename=FBSF201002020

Zhang, D. (2005). The enterprises'strategic management. Beijing: mechanical industry press.

Zhang, Z. (2000). The comparative advantage-China's automobile industry policy, the mode and the strategy. Tsinghai university press. 


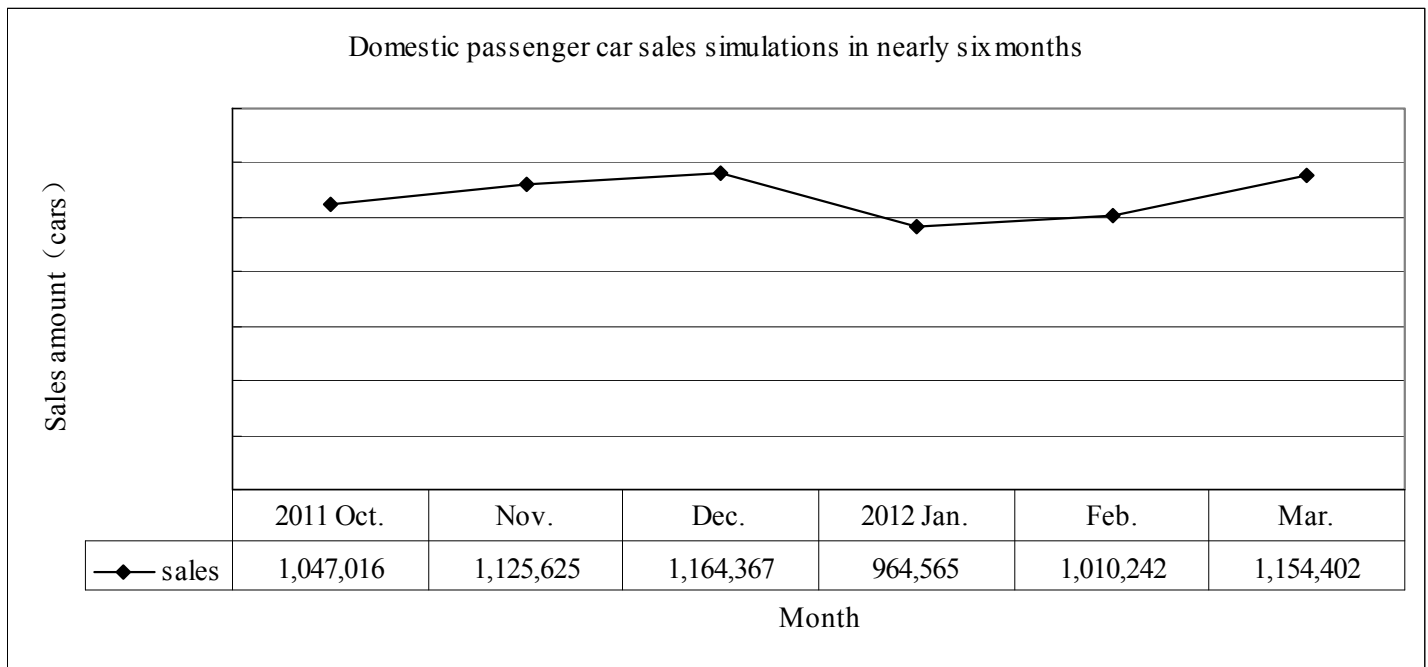

Figure 1. China domestic automobile sales simulations in nearly six months

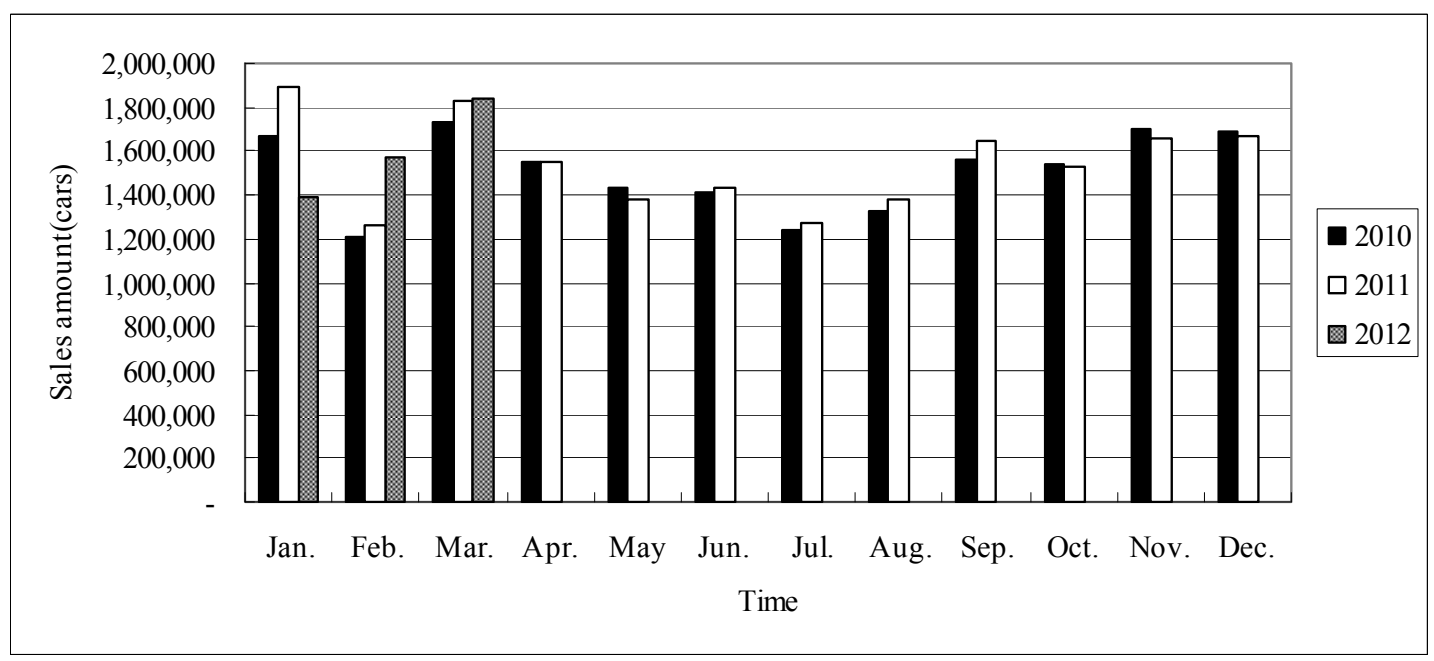

Figure 2. China's automobile sales from 2010 to 2012

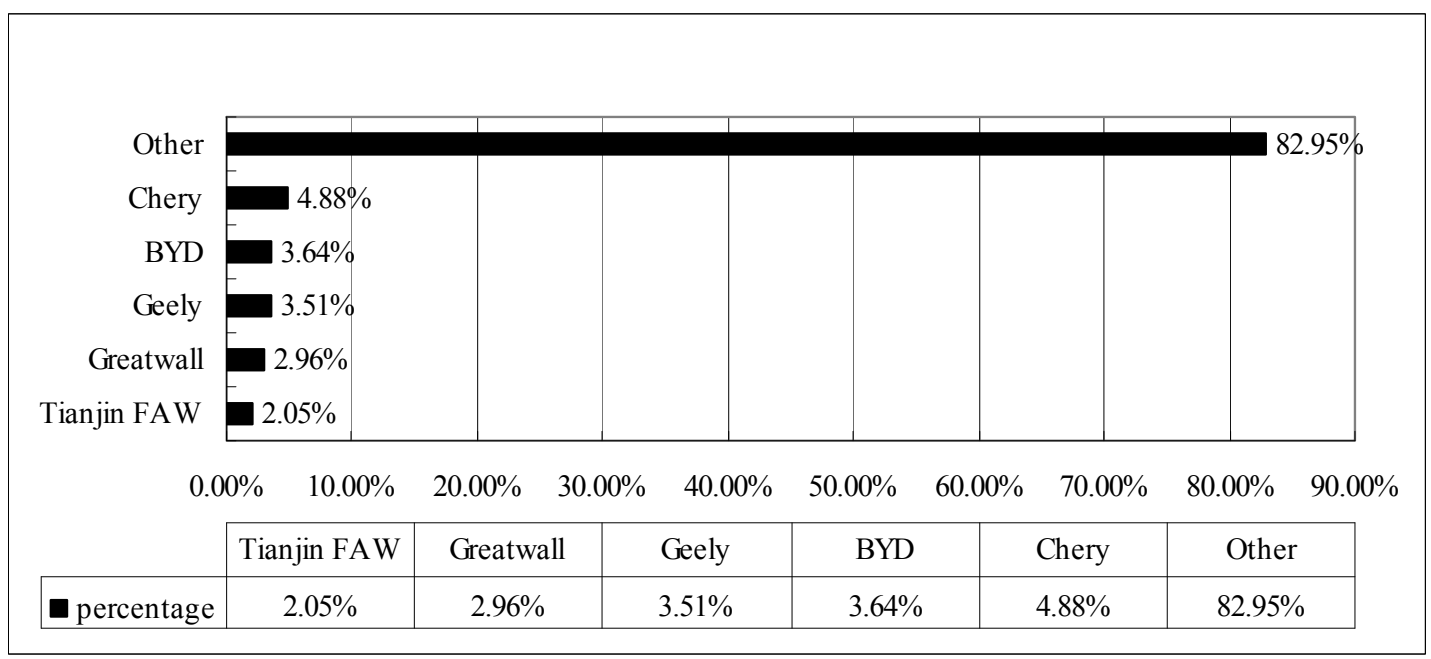

Figure 3. China's domestic automobile market share 


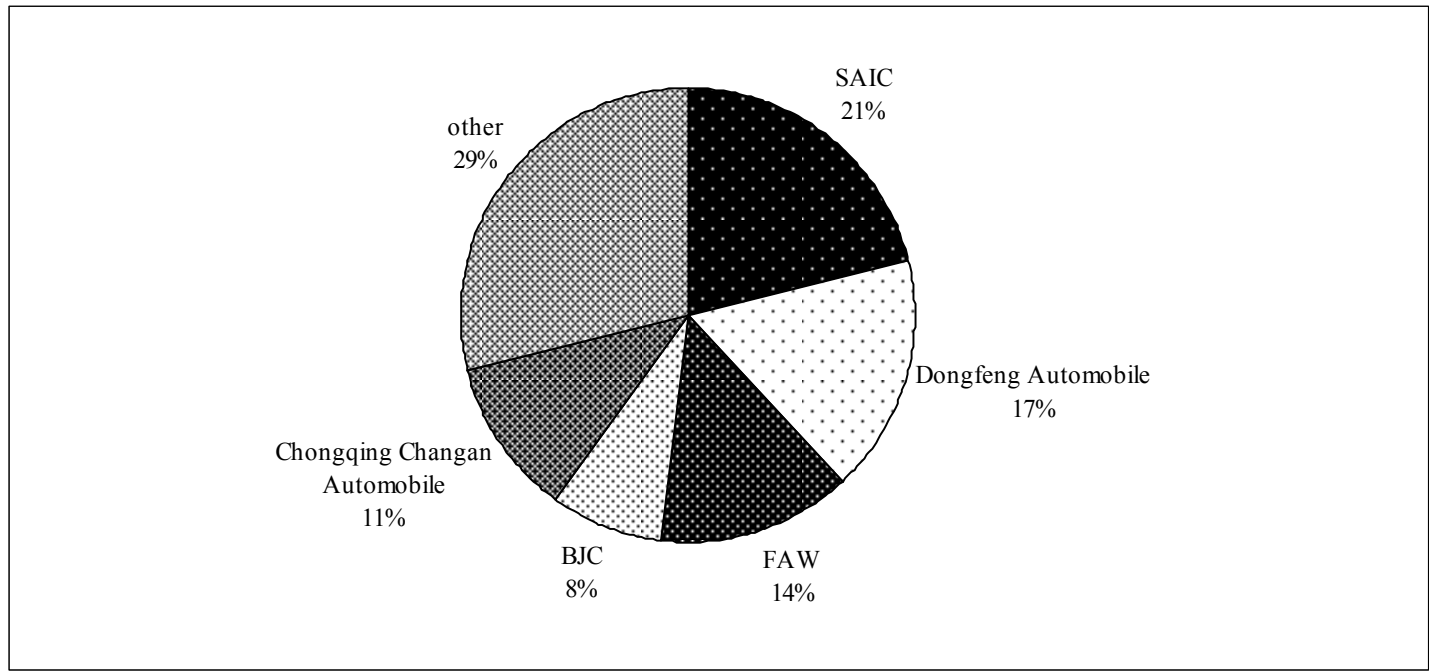

Figure 4. China domestic automobile sales market share in 2011

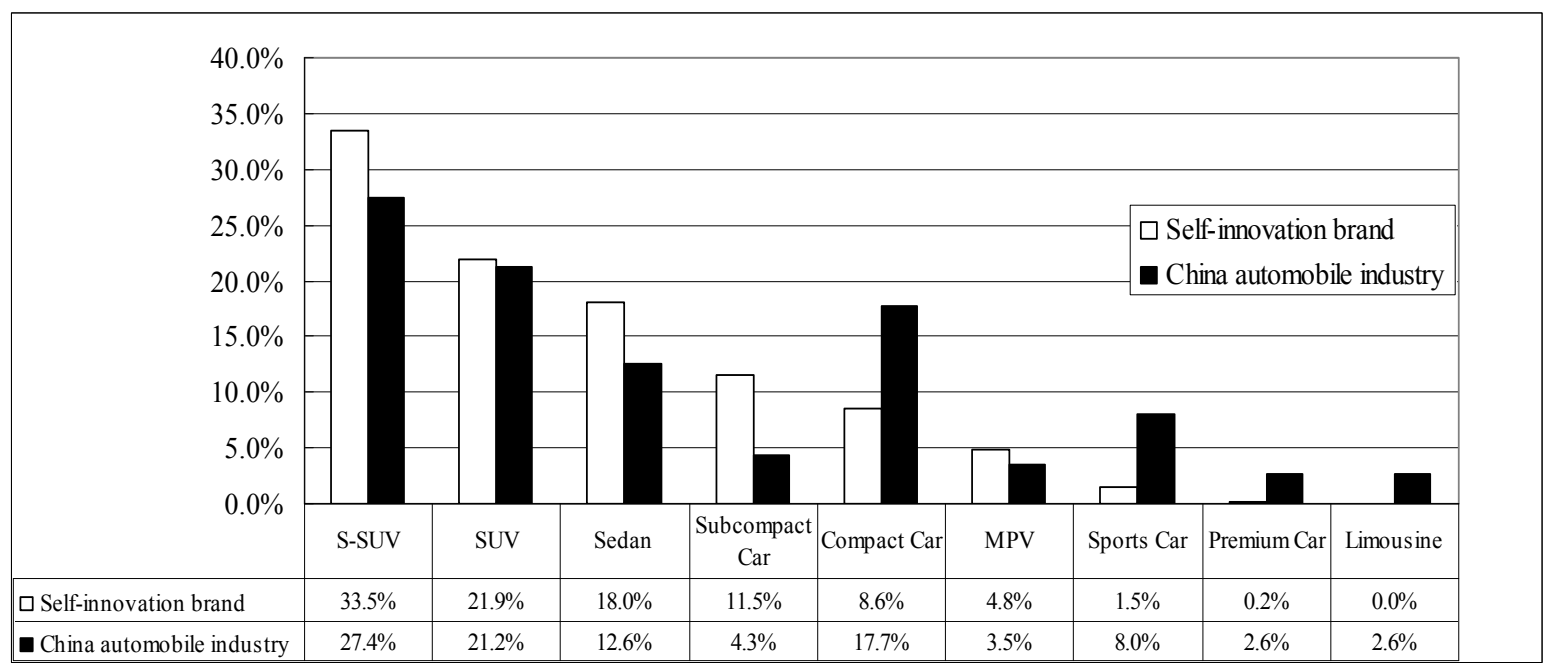

Figure 5. The compare of self-innovation brand with overall China automobile industry 